Check for updates

Cite this: RSC Adv., 2019, 9, 2332

\title{
Super stretchable chromatic polyurethane driven by anthraquinone chromogen as a chain extender
}

\begin{abstract}
Caiyun Zhao, ${ }^{a}$ Chaoxia Wang, (iD *a Youjiang Wang ${ }^{b}$ and Donggang Yao ${ }^{b}$
A novel polyurethane elastomer (PUE) that exhibited high tensile strength, large elongation at break, great color strength and supreme color fastness was successfully designed and synthesized. The PUEs were prepared with isophorone diisocyanate (IPDI) as hard segments, polycarbonate diol (PCDL)/ polytetrahydrofuran glycol (PTHF) as mixed soft segments, and anthraquinone chromogen as the chain extender agent. The relationships between the mechanical properties/color performance and chromogen addition content were investigated. The chromogen actual access rate of the obtained BPUEs was evaluated by UV-Vis. The clear tortuous surface and entanglements were exhibited in PUEs micromorphology structure, indicating a significant reinforcement of mechanical properties. Elongationat-break and tensile strength reached the maximum value $2394 \%$ at $1 \%\left(\mathrm{BPUE}_{1}\right.$ ) and $18.29 \mathrm{MPa}$ at $5 \%$ $\left(\mathrm{BPUE}_{5}\right)$, respectively, and then decreased as chromogen addition content increased. Mechanical testing results correlate well with XRD and SEM findings, which proved that anthraquinone chromogen induced an improvement in phase separation. Furthermore, BPUE films displayed high color strength and excellent color fastnesses. The rubbing fastness and washing fastness of $B P U E_{1}$ and $B P U E_{0.5}$ reached grade 5, respectively. These inspiring findings suggest that PUE films with superb performance have potential to be directly applied in the textile field.
\end{abstract}

Received 11th August 2018

Accepted 23rd December 2018

DOI: $10.1039 / \mathrm{c} 8 \mathrm{ra06744a}$

rsc.li/rsc-advances reinforce PUE. The hardness and tensile strength of PUE are increased with the presence of more hard segments while the stretchability is decreased with a reduction in soft segments. ${ }^{12,13}$ Consequently, it is difficult to improve the stretchability of PUE without sacrificing its tensile strength. However, it is highly desirable to develop a PUE with outstanding tensile strength as well as stretchability by controlling its phase separations.

PUEs are considered ideal materials for fabricating soft and smart textile materials which require soft and deformable properties to establish safe and flexible interactions with humans, externally and internally. ${ }^{18-22}$ PUEs with easyprocessing performance can meet a wide range of needs for numerous applications. To produce waterproofing breathable coating for fabrics with highly hydrophilic waterborne polyurethanes, Kim et al. investigated a new approach for PUE synthesis in which 4'4-diisocyanato dicyclohexylmethane ( $\left.\mathrm{H}^{12} \mathrm{MDI}\right)$ is employed as a diisocyanate, accompanied by PEG/ DMPA as a hydrophilic/ionic component, ethylenediamine (EDA) as a chain extender, and aliphatic triisocyanate as a hardener. ${ }^{23}$ A series of polyurethane-urea based liquid bandage materials with suitable softness, good elasticity, moisture absorption, and water vapor permeability were prepared from $\mathrm{H}^{12} \mathrm{MDI}$ as an aliphatic diisocyanate, hydrophilic PEG/hydrophobic PDMS blend as a soft segment and EDA as a chain extender. ${ }^{24}$ Most PUEs exhibit relatively low strain at break, poor wearing-comfort as textiles, and are not suitable to be used as textile fabrics.
${ }^{a}$ Key Laboratory of Eco-Textile, Ministry of Education, School of Textile \& Clothing, Jiangnan University, Wuxi 214122, People's Republic of China. E-mail: wangchaoxia@sohu.com; Fax:+86-0510-85912105; Tel: +86-0510-85912105 ${ }^{b}$ School of Materials Science \& Engineering, Georgia Institute of Technology, Atlanta, GA 30332-0295, USA

$\dagger$ Electronic supplementary information (ESI) available. See DOI: 10.1039/c8ra06744a 
Traditional colored PUEs are manufactured with a mixture of pigments and PUE matrix. Many additives are added to improve pigment dispersion uniformity. The physical blending method brings some problems, including poor compatibility between pigments and PUE matrix, due to the multiple phase reaction system. Meanwhile, PUE may also be dyed with an acid dye or a disperse dye at a relatively high temperature of $90-100{ }^{\circ} \mathrm{C}$ and a long time of 50-60 min, in a complex and time consuming process. Colored PUE films from such processes usually show a poor color fastnesses and color stability. To overcome these limitations, efforts have been made in the literature to synthesize colored PU with chromogens covalently bonded to the polymer chain. ${ }^{25-27}$ A series of stable and homogeneous blue waterborne polyurethanes were developed using colorant diols as chain extender. Experimental results indicate that the increase of colorant diol content will substantially increase the tensile strength without significantly decreasing the elongation of polyurethanes. ${ }^{25}$ Mao et al. successfully synthesized waterborne polyurethane polymeric dyes with excellent color properties. ${ }^{\text {26-29 }}$

The present work aims at the fabrication of a new PUE suitable for textile applications with not only excellent color properties but also good tensile strength and high stretchability. In the elastomer design, isophorone diisocyanate (IPDI) is used as hard-segments, meanwhile polycarbonate diol $\left(\mathrm{PCDL}, M_{\mathrm{n}}=2000\right)$ and polytetrahydrofuran glycol (PTHF, $M_{\mathrm{n}}=$ 2000) are employed as mixed soft-segments. Moreover, various compositions are explored to examine the effect of anthraquinone chromogen and other factors (such as crystallinity and phase separation) on mechanical properties of the PUEs. A novel approach is proposed to synthesize super stretchable chromatic polyurethane elastomer by introducing anthraquinone chromogen as chain extender for potential applications in textile field, such as elastic fiber (SPANDEX), film materials, fabric coating composite colorant, composite materials hightemperature modifier.

\section{Experimental}

\section{Materials and methods}

Isophorone diisocyanate (IPDI) and polytetrahydrofuran glycol 2000 (PTHF2000) were bought from Aladdin (Shanghai) Co., Ltd. Polycarbonate diol 2000 (PCDL2000) was procured from Nanjing Chemical Material Corporation Co., Ltd. The 1-((2hydroxyethyl)amino)-4-(methylamino)-10-anthracenedione

( $\mathrm{NH}$-blue-OH, as shown in Scheme 1) in a raw powder form was acquired from FILO Color \& Chemicals (Wuxi) Co., Ltd. Dibutyltin dilaurate (DBTDL) and acetone were all obtained from Sinopharm Chemical Reagent Co., Ltd. Acetone was dried with $\mathrm{CaH}_{2}$ and always kept with 4A molecular sieves before utilization.

\section{Synthesis of PUEs}

The PUEs were synthesized by a pre-polymerization method, as shown in Fig. 1 and Scheme 1. The PCDL and PTHF were dried with dry nitrogen under reduced pressure. PCDL was

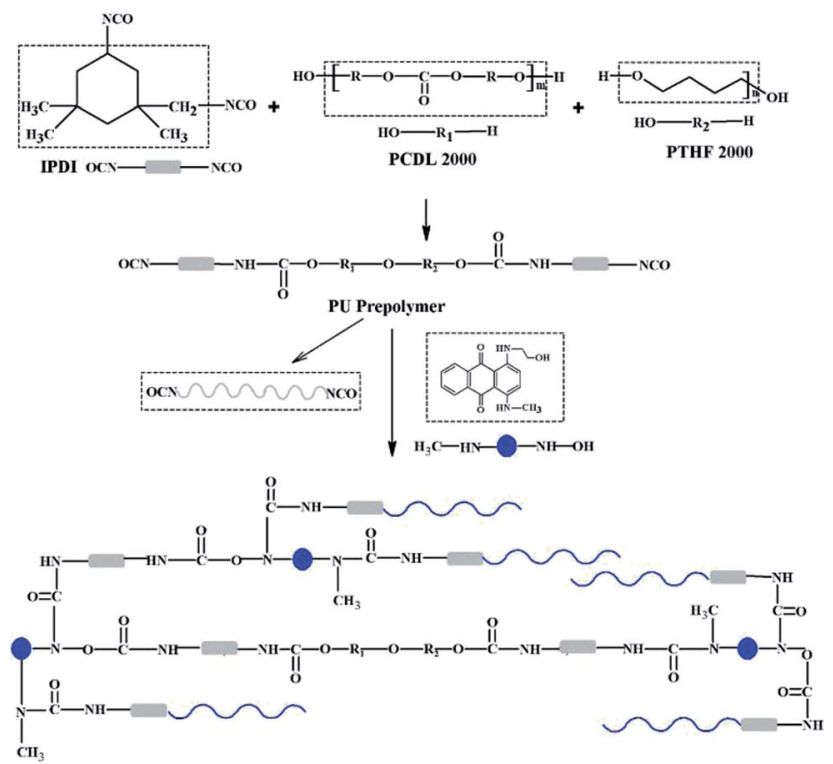

Scheme 1 Synthesis process and chemical structure of the BPUEs.

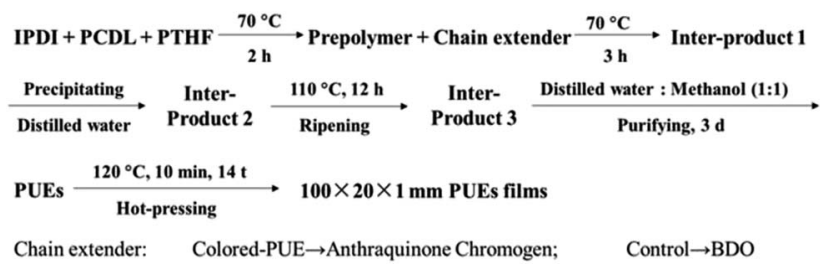

Fig. 1 Synthesis route of PUE films (chain extender: anthraquinone chromogen for BPUEs, BDO for control).

used as the major soft segment ( $80 \mathrm{~mol} \%)$ and blended with PTHF (20 mol\%) at the beginning of the synthesis. Prepolymers were prepared from PCDL/PTHF and IPDI with a ratio of $\mathrm{K}=[\mathrm{NCO}] /[\mathrm{OH}]=[\mathrm{IPDI}] /[\mathrm{PCDL} / \mathrm{PTHF}]=5 /[3 / 1]$ at $70{ }^{\circ} \mathrm{C}$ for $2 \mathrm{~h}$ under a nitrogen atmosphere. The extent of the reaction was determined by an amine equivalent method. After the prepolymerization was finished, the prepolymer and chain extender $\mathrm{NH}$-blue- $\mathrm{OH}$ reacted at $70{ }^{\circ} \mathrm{C}$ for $2 \mathrm{~h}$ and then the catalyst DBTDL was added to enhance the reaction for $1 \mathrm{~h}$. At last, the reaction products (inter-products 1) were precipitated in water solution. Then, they were poured into molds constructed of Teflon plates.

\section{Preparation of PUEs films}

The inter-products 1 were cut into pieces and thoroughly washed with magnetic stirring for $3 \mathrm{~d}$ in $50 \%$ distilled water and $50 \%$ methanol $(2 \mathrm{~L} \times 3)$ to remove any remaining chromogens, which were named as inter-products 2 . Then the PUEs were suction filtered and ripened at $110{ }^{\circ} \mathrm{C}$ for $12 \mathrm{~h}$, which were marked as inter-products 3 . Finally, $100 \times 20 \times 1 \mathrm{~mm}$ PUEs films were prepared through hot-pressing at $120{ }^{\circ} \mathrm{C}$.

When the chain extender $\mathrm{NH}-$ blue- $\mathrm{OH}$ was replaced by $1,4-$ butylene glyco (BDO), the product was marked as control. The 
NH-blue-OH mole ratio of PUEs were $0,0.5 \%, 1.0 \%, 5.0 \%$, and $10.0 \%$, respectively, corresponding to the samples which were named control, $\mathrm{BPUE}_{0.5}, \mathrm{BPUE}_{1}, \mathrm{BPUE}_{5}$, and $\mathrm{BPUE}_{10}$.

\section{Analytical methods}

UV-visible absorption spectroscopy. Suitable aliquots of anthraquinone chromogen and PUE tetrahydrofuran (THF) solutions, kept at room temperature, were transferred to $10 \mathrm{~mL}$ volumetric flasks. The absorbance of each solution was measured ( $1 \mathrm{~cm}$ cell) by a UV-visible Spectrophotometer (Cary 50 , Varian) within the wavelength range of 200 and $800 \mathrm{~nm}$.

ATR-IR characterization of PUEs films. The structures of 1((2-hydroxyethyl)amino)-4-(methylamino)-10-anthracenedione (NH-blue-OH) monomolecular chromogen and the PUEs films were recorded using an attenuated total reflection infrared spectroscope (NicoletiS10, Thermo Scientific, Co. Ltd, China) in the scanning range of $4000-500 \mathrm{~cm}^{-1}$ with a resolution of $4 \mathrm{~cm}^{-1}$.

Molecular weight. Gel permeation chromatography (GPC, Waters 1515 Isocratic HPLC, USA) was used to estimate the molecular weight of the PUEs with solvent dimethyl formamide (DMF) at room temperature. The molecular weight spectrogram was then recorded in 190-800 nm scanning wavelength and 0$20 \mathrm{~cm}^{3} \mathrm{~min}^{-1}$ flow rate. The number-average molecular weight, $M_{\mathrm{n}}$, and the dispersity of the PUEs (solutions in DMF, $1 \mathrm{~g} \mathrm{dL}^{-1}$ ) were determined.

XRD. Wide Angle X-ray Diffraction (WAXD) testing was performed on a Shimadzu XRD-6100 Diffractometer, using the Nifiltered $\mathrm{Cu}-\mathrm{K} \alpha$ radiation $\left(1 \frac{1}{4} 0.1541 \mathrm{~nm}\right)$. The test condition was $36 \mathrm{kV}$ and $30 \mathrm{~mA}$. All the diffractograms were investigated in the range $2-50^{\circ}(2 \theta)$ at room temperature. The $d$-spacings were calculated from Bragg's equation as follows:

$$
\lambda=2 d \sin \theta
$$

where $\lambda$ is the wavelength of the incident X-ray beam; $d$ is the distance between adjacent planes of atoms ( $d$-spacing) and $\theta$ is the angle of incidence of the X-ray beam.

Color properties (color strength, color fastness). The color properties are normally characterized by a set of parameters, such as $K / S$ value, $L^{*}, a^{*}, b^{*}$, which were measured using an Xrite-8400 spectrophotometer under the illuminant D65 using a $10^{\circ}$ standard observer. $K / S$ value represents the relative color strength. The rubbing fastnesses of PUE films were tested according to AATCC 8-2007. PUE films were separately rubbed for 50 cycles with dry and wet (moisture content 95-105\%) standard crocking cloth under $9 \mathrm{~N}$ vertical pressure by a crocking fastness tester (Y571, Electron Instrument Co., Ltd., Laizhou, China). The washing fastnesses were measured on the basis of AATCC Test Method 61-2006 standard with $5 \mathrm{~g} \mathrm{~L}^{-1}$ soap and $2 \mathrm{~g} \mathrm{~L}^{-1} \mathrm{Na}_{2} \mathrm{CO}_{3}$ at $60{ }^{\circ} \mathrm{C}$ for $30 \mathrm{~min}$ using a washing fastness tester (Wenzhou Darong Textile Instrument Co., Ltd., China). The PUE films were immersed in $10 \% \mathrm{H}_{2} \mathrm{SO}_{4}$ and $10 \% \mathrm{NaOH}$ solutions for $24 \mathrm{~h}$ at $37{ }^{\circ} \mathrm{C}$, respectively. After removing the excess surface solutions with filter paper, the weight of the swollen sample was dried until there was no further decrease in weight. The weight loss represents the acid and alkali resistance of PUE films.

Mechanical properties. Tests for mechanical properties were performed on an Instron 5967 testing machine. Five dumb-bell shaped testing specimens of each sample were tested. Uniaxial tensile tests were carried out at a rate of $50 \mathrm{~mm} \min ^{-1}$ until specimen failure. The Young's modulus were calculated as the slope at the initial linear region.

Shore A hardness measurements were carried out on a AICE A:90 digital hardness testing apparatus at room temperature following ASTM A 2240 standard.

Morphologies of PUEs. The surface morphologies of PUEs films were observed with a scanning electron microscope (SEM, TM3030, Hitachi). The specimens were coated with a thin layer of gold.

Thermal analysis. Differential scanning calorimetry (DSC) measurements were recorded on a TA instrument (Q200, United States) thermal analyzer. Liquid aluminum crucibles containing 3-5 mg of PUE samples were heated from $-80{ }^{\circ} \mathrm{C}$ to $300{ }^{\circ} \mathrm{C}$ at a heating rate of $10{ }^{\circ} \mathrm{C} \mathrm{min}^{-1}$ in nitrogen atmosphere.

\section{Results and discussion}

Polyurethanes elastomers (PUEs) consist of hard segments and soft segments. In this work, polycarbonate diol (PCDL) and polytetrahydrofuran glycol (PTHF) were used as mixed soft segments, providing excellent film forming property and stretchability. Because 1-((2-hydroxyethyl)amino)-4(methylamino)-10-anthracenedione (NH-blue-OH) was a component forming the hard segments, the $\mathrm{NH}-$ blue- $\mathrm{OH}$ content will affect the properties of PUEs.

\section{Quantitative analysis of NH-blue-OH (UV-Vis)}

PUEs films for UV-Vis spectra analysis were fabricated by casting the solution on quartz cells. UV-Vis absorption spectra of $\mathrm{NH}$-blue-OH tetrahydrofuran (THF) solutions are presented corresponding to five levels of $\mathrm{NH}$-blue-OH concentrations of $25 \mu \mathrm{M}, 50 \mu \mathrm{M}, 100 \mu \mathrm{M}, 200 \mu \mathrm{M}$ and $400 \mu \mathrm{M}$. Two absorbance maxima at the wavelengths of $596.50 \mathrm{~nm}$ and $644.00 \mathrm{~nm}$ can be observed in Fig. 2 .

There are two absorbance maxima in every UV-Vis absorption spectra in Fig. 2 and the averages of absorbance at the wavelengths of $596.50 \mathrm{~nm}$ and $644.00 \mathrm{~nm}$ are analyzed by linear regression. A linear equation for the calibration spectra was obtained by liner regressing analysis based on the spectra of different $\mathrm{NH}$-blue-OH concentrations in THF solution as shown in Fig. 3, with a correlation coefficient $\left(R^{2}\right)$ of $99.9 \%$.

The same absorption peaks can also be observed in the spectra of BPUEs dissolved in THF solutions, as shown in figure. Since the absorption spectra of BPUEs in THF solutions (Fig. 4) correspond to the spectra of $\mathrm{NH}-$ blue-OH THF solutions (Fig. 2), the absorption spectra of Fig. 2 can be used for quantitative analysis of $\mathrm{NH}$-blue- $\mathrm{OH}$ reaction rate with the aid of chemometrics methods. The difference in magnitude between the experimental and calculated values is below $5 \%$. 


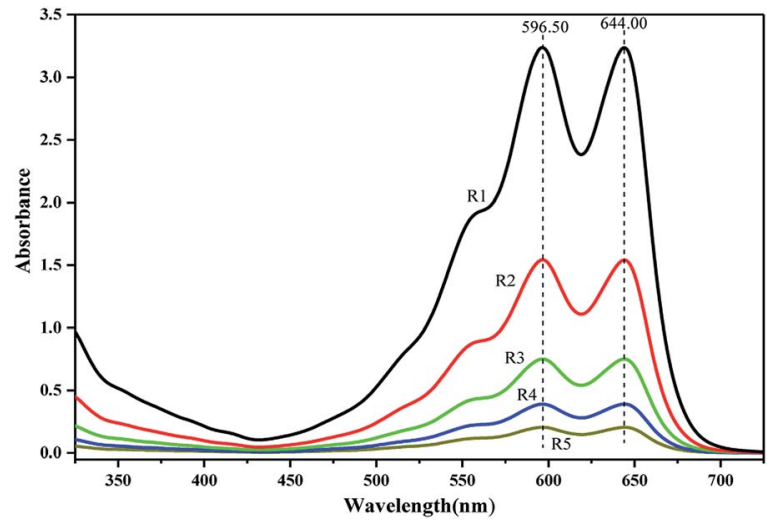

Fig. 2 Absorption spectra of different $\mathrm{NH}$-blue-OH concentrations in THF solution.

As displayed in Fig. 4, the maximum absorption wavelengths $\left(\lambda_{\max }\right)$ exhibit at $598.60 \mathrm{~nm}$ and $644.00 \mathrm{~nm}$, associating with the anthraquinone chromophore and auxochrome groups. It can be seen from Fig. 2 and 4, the THF solutions of BPUEs and the NHblue-OH monomolecular dye show similar absorption curves in the ultraviolet region and visible region, demonstrating that $\mathrm{NH}-$ blue-OH has been successfully introduced into the BPUEs chain. Furthermore, the $\lambda_{\max }$ of $\mathrm{BPUE}_{10}, \mathrm{BPUE}_{5}, \mathrm{BPUE}_{1}$ and $\mathrm{BPUE}_{0.5}$, are the same as that of individual $\mathrm{NH}-$ blue-OH. Since no bathochromic or hypsochromic shift of $\lambda_{\max }$ is observed between the NH-blue-OH monomer dye and BPUEs, it has no significant effect on the $\mathrm{n}-\pi^{*}$ and $\pi-\pi^{*}$ transitions in the anthraquinone unit whether the $\mathrm{NH}-$ blue-OH group is introduced into the PUEs chain or not. In general, a hypsochromic shift appears mainly because the auxochromic groups $\left(-\mathrm{NH}_{2}\right)$ directly conjugated with anthraquinone react with $-\mathrm{NCO}$ and therefore influence the $\mathrm{n}-\pi^{*}$ and $\pi-\pi^{*}$ transitions in the aromatic rings. Thus, if the active groups did not directly link with the chromophore, the $\lambda_{\max }$ would not change after the $\mathrm{NH}-$ blue-OH monomer was embedded into the BPUEs chain.

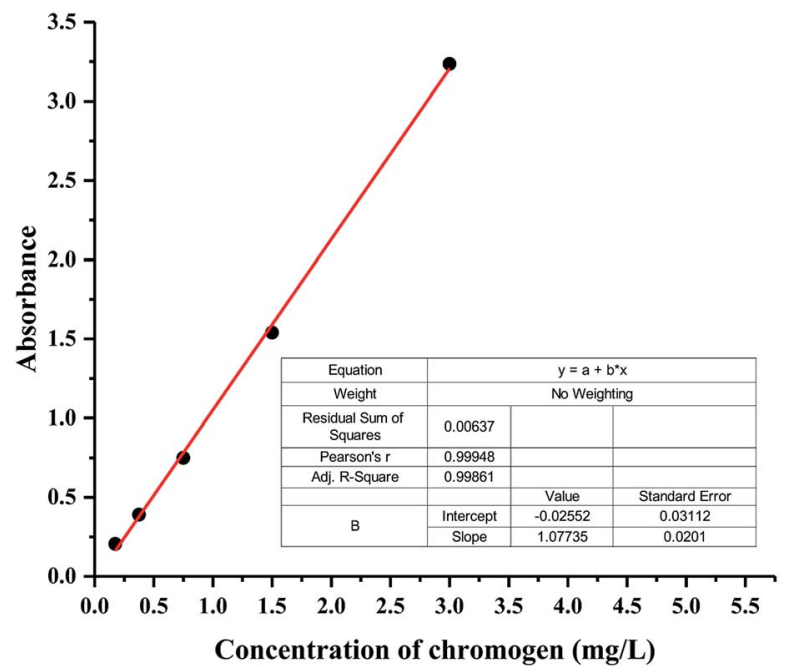

Fig. 3 Calibration spectra of different $\mathrm{NH}$-blue-OH concentrations in THF solution.

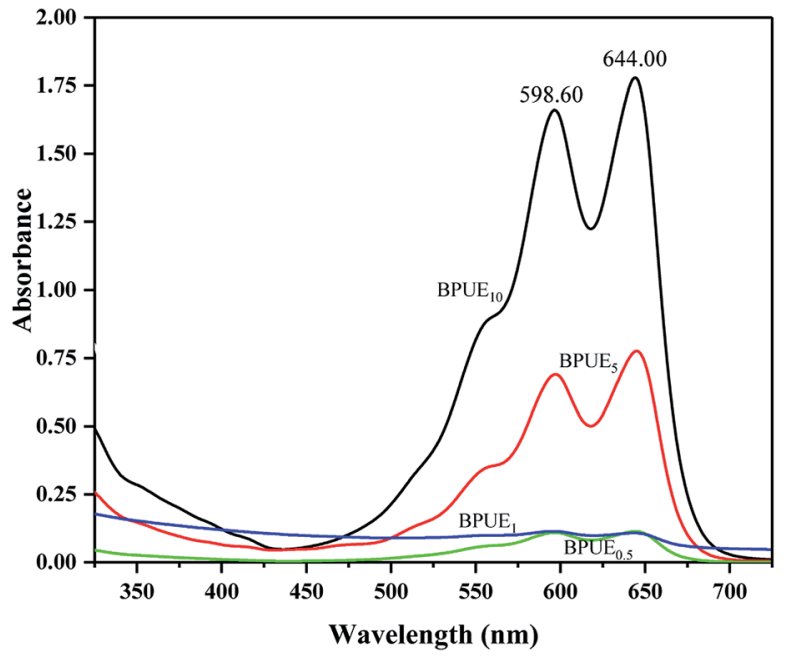

Fig. 4 Absorption spectra of the BPUEs in THF solution.

Table 1 Chromogen conversion rates of BPUEs

\begin{tabular}{|c|c|c|c|c|c|}
\hline \multirow[b]{2}{*}{ Sample } & \multicolumn{2}{|c|}{$\begin{array}{l}\text { Wavelength } \\
(\mathrm{nm})\end{array}$} & \multirow{2}{*}{$\begin{array}{l}\text { Theoretical } \\
\text { mass (\%) }\end{array}$} & \multirow{2}{*}{$\begin{array}{l}\text { Actual mass } \\
(\%)\end{array}$} & \multirow{2}{*}{$\begin{array}{l}\text { Actual conversion } \\
\text { rate }(\%)\end{array}$} \\
\hline & 598.60 & 644.00 & & & \\
\hline BPUE $_{10}$ & 1.666 & 1.784 & 3.150 & 1.578 & 50.10 \\
\hline BPUE $_{5}$ & 0.689 & 0.785 & 0.953 & 0.594 & 62.33 \\
\hline $\mathrm{BPUE}_{1}$ & 0.109 & 0.114 & 0.324 & 0.211 & 65.12 \\
\hline BPUE $_{0.5}$ & 0.114 & 0.108 & 0.256 & 0.240 & 93.85 \\
\hline
\end{tabular}

As seen in Table 1, the actual mass percentages of $\mathrm{BPUE}_{0.5}$, $\mathrm{BPUE}_{1}, \mathrm{BPUE}_{5}$, and $\mathrm{BPUE}_{10}$ are $0.240 \%, 0.211 \%, 0.594 \%$ and $1.577 \%$ respectively, which were calculated according to the absorbance values of $\lambda_{\max }$. The theoretical mass values of $\mathrm{BPUE}_{0.5}, \mathrm{BPUE}_{1}, \mathrm{BPUE}_{5}$, and $\mathrm{BPUE}_{10}$ are $0.256 \%, 0.324 \%$, $0.953 \%$ and $3.150 \%$. Actual conversion rates can be obtained by comparing the theoretical mass values and the actual mass values. The chromogen actual conversion rate of $\mathrm{BPUE}_{0.5}$ was $93.85 \%$, which confirmed that when the mole ratio of NH-blue$\mathrm{OH}$ was $0.5 \%$ it nearly all the chromogen was reacted.

\section{Structure characterization}

ATR-IR absorption spectra of PUE films and NH-blue-OH chromogen are displayed in Fig. 5. The absorption peaks corresponding to $\mathrm{NH}$-blue-OH molecular chromogen are observed at around $3433 \mathrm{~cm}^{-1}(-\mathrm{OH}), 3213 \mathrm{~cm}^{-1}(-\mathrm{NH}-), 2924-$ $2853 \mathrm{~cm}^{-1}\left(-\mathrm{CH}_{2}-,-\mathrm{CH}_{3}\right), 1737 \mathrm{~cm}^{-1}(\mathrm{C}=\mathrm{O}), 1600-1425 \mathrm{~cm}^{-1}$ $\left(\mathrm{C}=\mathrm{C}\right.$, anthraquinone ring), $1201 \mathrm{~cm}^{-1}(\mathrm{C}-\mathrm{N}), 1017 \mathrm{~cm}^{-1}(\mathrm{C}-\mathrm{H}$ in-plane bending vibration, anthraquinone ring) and $804 \mathrm{~cm}^{-1}$ (C-H out-plane bending vibration, anthraquinone ring). The appearance of strong bands at around $1017 \mathrm{~cm}^{-1}$ and $804 \mathrm{~cm}^{-1}$ due to $\mathrm{C}-\mathrm{H}$ in-plane and out-plane bending vibrations in anthraquinone ring confirms that $\mathrm{NH}$-blue- $\mathrm{OH}$ chromogen has been successfully introduced into the polyurethane chains, ${ }^{30}$ as indicated by the UV-Vis results. The peaks at $1737 \mathrm{~cm}^{-1}$ and $1253 \mathrm{~cm}^{-1}$ are assigned to $\mathrm{C}=\mathrm{O}$ and $\mathrm{C}-\mathrm{O}$ in the carbonate 

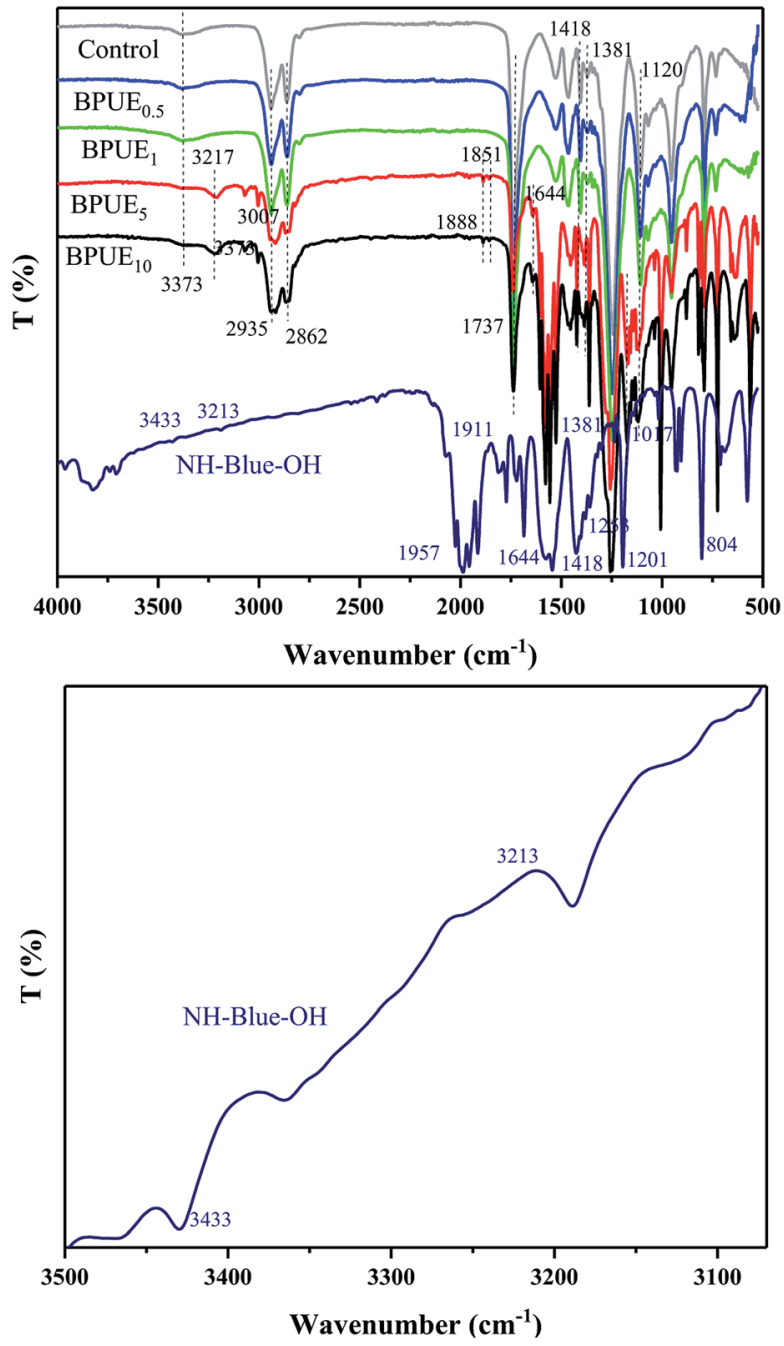

Fig. 5 ATR-IR spectra for different PUE films and $\mathrm{NH}-$ blue-OH chromogen.

group, and those at $3373 \mathrm{~cm}^{-1}, 1737 \mathrm{~cm}^{-1}$ and $1381 \mathrm{~cm}^{-1}$ correspond to the stretching band of $\mathrm{N}-\mathrm{H}, \mathrm{C}=\mathrm{O}$ and $\mathrm{C}-\mathrm{O}$ in the urethane group, while the peak at $1120 \mathrm{~cm}^{-1}$ is ascribed to the ether group. All the above peaks are associated with the formation of polyurethane chains. ${ }^{31}$ Additionally, the absence of characteristic stretching vibration at $2270 \mathrm{~cm}^{-1}(-\mathrm{NCO})$ reveals that isocyanate groups have been completely exhausted.

ATR-IR absorption spectra is frequently used to analyze structural changes in the polyol polyurethane networks both qualitatively and quantitatively. As displayed in Fig. 5, there is no obvious peak in $2270 \mathrm{~cm}^{-1}$ region for all PUE films, indicating that all -NCO groups were consumed during the reaction.

In order to compare different samples, all absorbance peaks were normalized with respect to the carbonyl hydrogen bonding (around $1737 \mathrm{~cm}^{-1}$ ), because this peak changed with the amount of hydrogen bonding. Amrollahi et al. ${ }^{32}$ reported that hydrogen bonding index increases with no hard segment content (hydrogen bonding) due to thermodynamic incompatibility of hard and soft segments in polyurethanes. Moreover,

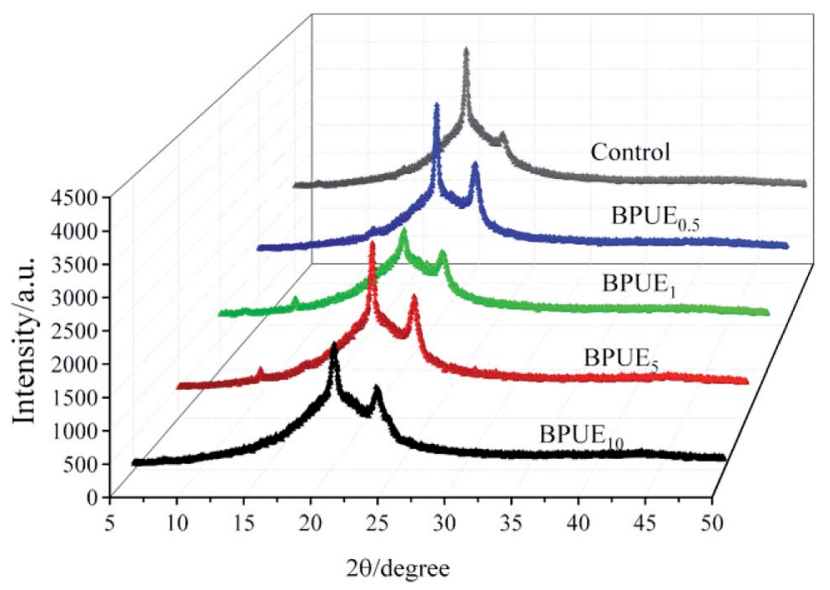

Fig. 6 X-ray diffraction patterns of PUE films.

Chen et $a l .{ }^{33}$ showed that steric shielding and crowding lead to some - NH- groups with no hydrogen bonding interaction in polyurethane system. This phenomenon could be caused by two factors, the chemical interaction (crosslinking) and the length of soft segments. Through quantitative analysis, it can be seen that with the increasing $\mathrm{NH}-$ blue-OH mole ratio of BPUEs, the $1737 \mathrm{~cm}^{-1}$ absorption peak strength is increased, which further proves that the chromogen was successfully introduced into the polyurethane chains.

X-ray powder diffraction (XRD) testing was carried out to identify the difference of the crystalline structure among different PUEs (control, BPUE ${ }_{0.5}, \mathrm{BPUE}_{1}, \mathrm{BPUE}_{5}$, and BPUE $\mathrm{B}_{10}$ ). In the PUEs, the degree of phase separation between soft segments and hard segments varies with their relative contents, structural regularity and thermodynamics incompatibility. The addition of chromogen supports the formation of more ordered structure, as higher peak intensities are observed for the PUEs extended with chromogen than 1,4-butane diol (BDO). XRD curves of PUEs in Fig. 6 show that the intensity of the peak around $23.62^{\circ}(2 \theta)$ much depends on the concentration of chromogen in the polyurethane backbone.

It can be observed in Table 2 that increasing the chromogen content results in increased intensity of the peak around $23.62^{\circ}$ $(2 \theta)$ for the 200 lattice plane. This confirms that soft segments containing PCDL and PTHF tend to crystallize more easily so as to exhibit better distinct peaks. Additionally, the peaks for -111 lattice plane around $22.08^{\circ}(2 \theta)$ mainly based on IPDI are attributed to the hard segments. In general, the crystallinity of PUEs is provided by the soft segments. In term of hard segments, they have a higher polarity than soft segments and the hard segments formed structure of PUEs would be much less crystalline than the soft segments formed structure. It is worth mentioning that hard segments also present a relatively small diffraction peak at $11.48^{\circ}(2 \theta)$. The XRD patterns of the PUEs films indicate that a more ordered orientation structure is shown in these samples.

As it is reported, the molecular weight of PUs based on colorant diol/diamine as chain extender has significant effect on the properties. The molecular weight of PUEs also has an obvious impact on the color and other properties. 
Table 2 Crystallinity characteristics of PUE films

\begin{tabular}{llrrl}
\hline Sample & $2 \theta,^{\circ}$ & Crystal plane & $\mathrm{I}$ & PWH \\
\hline \multirow{2}{*}{ Control } & 20.11 & -111 & 838 & 0.466 \\
& 23.40 & 200 & 424 & 0.481 \\
BPUE $_{0.5}$ & 20.14 & -111 & 942 & 0.374 \\
& 23.44 & 200 & 321 & 0.703 \\
BPUE $_{1}$ & 20.32 & -111 & 1042 & 0.367 \\
& 23.66 & 200 & 653 & 0.728 \\
BPUE $_{5}$ & 11.48 & 006 & 106 & 0.306 \\
& 20.08 & -111 & 314 & 0.572 \\
& 23.29 & 200 & 386 & 0.802 \\
BPUE $_{10}$ & 11.48 & 006 & 83 & 0.237 \\
& 20.29 & -111 & 826 & 0.390 \\
& 23.57 & 200 & 522 & 0.725
\end{tabular}

The molecular weight of PUEs can be obtained via gel permeation chromatography. The number-average molecular weight $\left(M_{\mathrm{n}}\right)$, weight-average molecular weight $\left(M_{\mathrm{w}}\right)$ and polydispersity index (PDI) of PUEs are summarized in Table 3. The average molecular weight is closely related to the proportion of diisocyanates in IPDI and hydroxyl in PCDL2000/PTHF2000 and chain extender. Theoretically, when the proportion of $-\mathrm{NCO}$ and -OH groups is close to $1: 1$, the molecular weight of PUEs can increase infinitely. The - NCO groups of prepolymer and IPDI react with the $-\mathrm{OH}$ and $-\mathrm{NH}$ groups of chain extender until the -NCO groups are exhausted completely, reaching the end of polyreaction. As can be seen in Table 3, the $M_{\mathrm{n}}$ and $M_{\mathrm{w}}$ of the control are 164094 and 371 499, respectively, which is much larger than BPUEs. The polydispersity of control, $\mathrm{BPUE}_{0.5}$, $\mathrm{BPUE}_{1}, \mathrm{BPUE}_{5}$, and $\mathrm{BPUE}_{10}$ is $2.26,2.09,2.15,1.86$ and 1.72, indicating a relatively homogeneous distribution of molecular weight. Therefore, the study shows that the kinds of chain extender plays a very important role on $M_{\mathrm{n}}, M_{\mathrm{w}}$ and PDI of PUEs.

\section{Color property}

The chromatic values $(K / S)$ and color parameters $\left(L^{*}, a^{*}\right.$ and $\left.b^{*}\right)$ of the PUEs films were examined to investigate the influence of chromogen contents on the color properties. The results are shown in Fig. 7 and Table 4 . The $K / S$ vs. wavelength curves and maximum absorption wavelengths for the BPUE ${ }_{1}$ and $\mathrm{BPUE}_{0.5}$ films were similar despite the different in chromogen content.

The $K / S$ values of $\mathrm{BPUE}_{0.5}, \mathrm{BPUE}_{1}, \mathrm{BPUE}_{5}$, and $\mathrm{BPUE}_{10}$ films are $4.19,5.28,10.79$ and 10.99 , which show the $K / S$ values reduce by $61.87 \%, 51.96 \%, 1.82 \%$ and $0 \%$ as the chromogen contents increases from $0.5 \%, 1.0 \%$ to $5.0 \%, 10.0 \%$. The color

Table 3 PUEs molecular weight with different content of $\mathrm{NH}$-blue$\mathrm{OH}$ chromogen

\begin{tabular}{lrll}
\hline Sample & $M_{\mathrm{n}}$ & $M_{\mathrm{w}}$ & Poly dispersity \\
\hline Control & 164094 & 371499 & 2.26 \\
BPUE $_{0.5}$ & 138313 & 289646 & 2.09 \\
BPUE $_{1}$ & 175502 & 377007 & 2.15 \\
BPUE $_{5}$ & 79365 & 147402 & 1.86 \\
BPUE $_{10}$ & 68140 & 117283 & 1.72
\end{tabular}

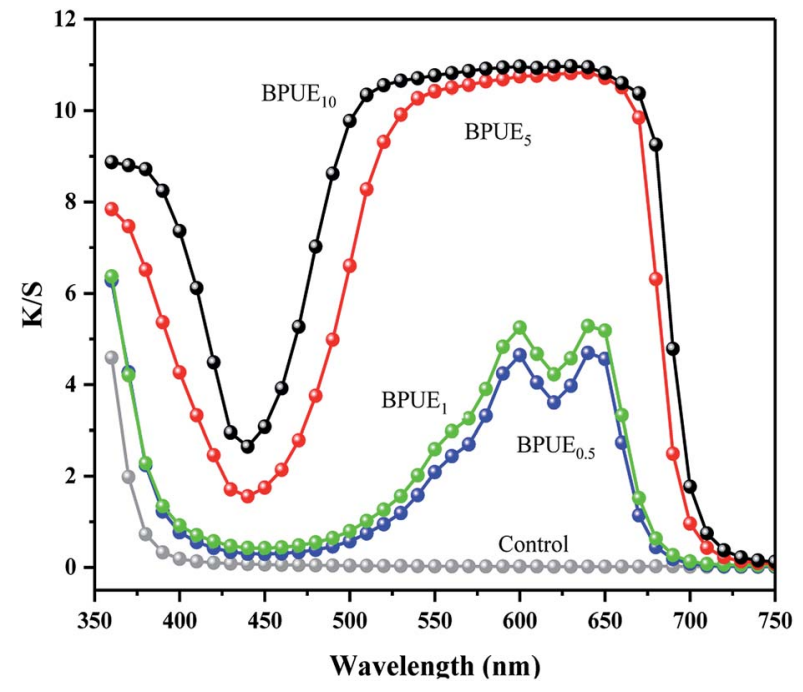

Fig. $7 \quad K / S$ value curves of PUE films.

lightness $\left(L^{*}\right)$ decrease with increasing chromogen addition molar ratio. In general, when $L^{*}$ is fixed, the red color value $\left(a^{*}\right)$ increase with increasing blue color value $\left(b^{*}\right)$. However, if the $L^{*}$ value is not constant and changes obviously, $a^{*}$ and $b^{*}$ values may not change regularly. The changes in these chromatic values and color parameters indicate that as the chromogen contents increase, the colors of the BPUE films turn dark and gloomy.

Table 4 Color properties of PUE films

\begin{tabular}{lcccr}
\hline Sample & $K / S$ value & $L^{*}$ & $a^{*}$ & \multicolumn{1}{c}{$b^{*}$} \\
\hline Control & 0.03 & 91.42 & -0.20 & 7.69 \\
BPUE $_{0.5}$ & 4.19 & 52.57 & -8.45 & -34.61 \\
BPUE $_{1}$ & 5.28 & 49.13 & -6.50 & -33.52 \\
BPUE $_{5}$ & 10.79 & 26.95 & 15.34 & -33.82 \\
BPUE $_{10}$ & 10.99 & 25.78 & 10.76 & -22.21
\end{tabular}

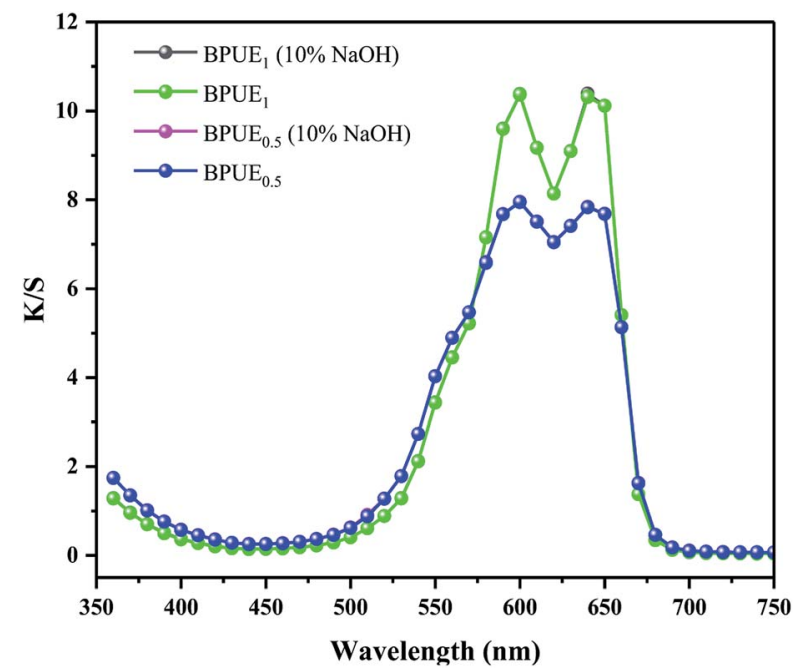

Fig. 8 Alkali resistance of $\mathrm{BPUE}_{1}$ and $\mathrm{BPUE}_{0.5}$ films (immersed in $10 \%$ $\mathrm{NaOH}$ for $24 \mathrm{~h}$ ) 


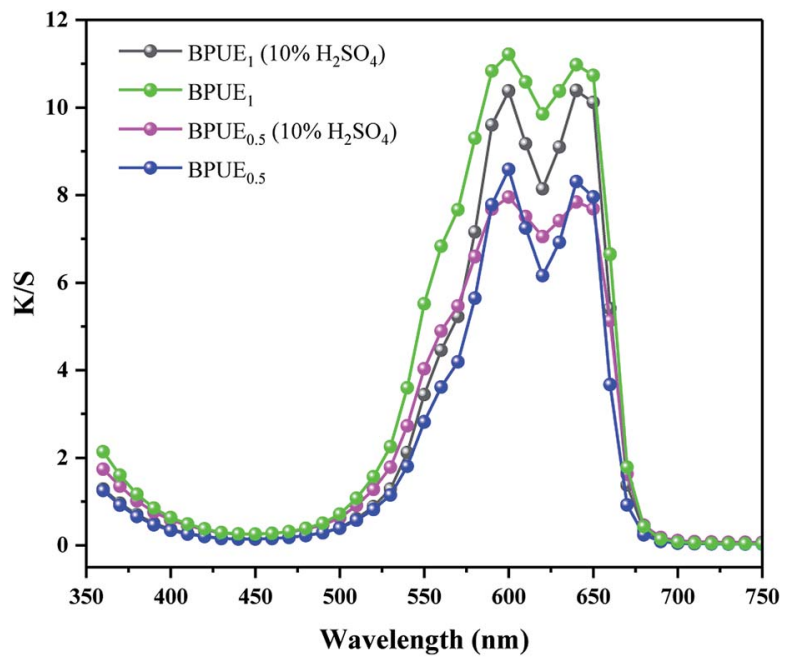

Fig. 9 Acid resistance of $\mathrm{BPUE}_{1}$ and $\mathrm{BPUE}_{0.5}$ films (immersed in $10 \%$ $\mathrm{H}_{2} \mathrm{SO}_{4}$ for $24 \mathrm{~h}$ ).

Color properties of $\mathrm{BPUE}_{1}$ and $\mathrm{BPUE}_{0.5}$ which were immersed in $10 \% \mathrm{H}_{2} \mathrm{SO}_{4}$ and $10 \% \mathrm{NaOH}$ solutions, respectively, for $24 \mathrm{~h}$ at $37{ }^{\circ} \mathrm{C}$ are shown in Fig. 8 and 9. The $K / S$ values of BPUE $_{1}$ and BPUE $_{0.5}$ are similar before and after being immersed in $10 \% \mathrm{NaOH}$, demonstrating good alkali resistance of $\mathrm{BPUE}_{1}$ and BPUE $_{0.5}$. There was a slightly change for the $K / S$ values of BPUE $_{1}$ and BPUE $_{0.5}$ after being immersed in $10 \% \mathrm{H}_{2} \mathrm{SO}_{4}$ as a small amount of chromogen was dissolved in the acid solutions, but overall good acid resistances of $\mathrm{BPUE}_{1}$ and $\mathrm{BPUE}_{0.5}$ was observed.

The color fastnesses of textiles are given in five grades, from grade 1 (severe loss) to grade 5 (no color change), and the results for the BPUE films are reported in Table 5. The rubbing and washing fastnesses of BPUE films changed from grade 5 for low chromogen content to grade 1 for high chromogen content. Color fastness mainly depends on the bonding strength between polymer chain and chromogen. The rubbing fastnesses of $\mathrm{BPUE}_{1}$ and $\mathrm{BPUE}_{0.5}$ are both grade 5 , whereas, the rubbing fastnesses of $\mathrm{BPUE}_{10}$ and $\mathrm{BPUE}_{5}$ are grade 1 . The $-\mathrm{NCO}$ groups in PUEs form hydrogen bonds with $-\mathrm{OH}$ active sites. However,
Table 5 Rubbing and washing fastnesses of BPUEs films

\begin{tabular}{llllll}
\hline & \multicolumn{2}{l}{$\begin{array}{l}\text { Rubbing } \\
\text { fastnesses }\end{array}$} & & & \multicolumn{2}{l}{ Washing fastnesses } \\
\cline { 2 - 3 } \cline { 5 - 6 } Sample & Dry & Wet & & Change & Staining \\
\hline BPUE $_{0.5}$ & 5 & 5 & & 5 & 5 \\
BPUE $_{1}$ & 5 & 5 & & 5 & 5 \\
BPUE $_{5}$ & 1 & 2 & & - & - \\
BPUE $_{10}$ & 1 & 1 & & - & -
\end{tabular}

excessive -NCO groups often conduct self-polymerization and the product tends to accumulate on the film surface, which can easily fall off from the films in rubbing or washing process. This explains why the color fastnesses of $\mathrm{BPUE}_{1}$ and $\mathrm{BPUE}_{0.5}$ with low chromogen content are superb. Another interesting point is that the shape and thickness of BPUE $_{1}$ films after washing remain unchanged from their original dimensions (Fig. 10). Therefore, the $\mathrm{BPUE}_{1}$ and $\mathrm{BPUE}_{0.5}$ films with superior color properties and fastnesses have the potential to be directly used as fabrics.

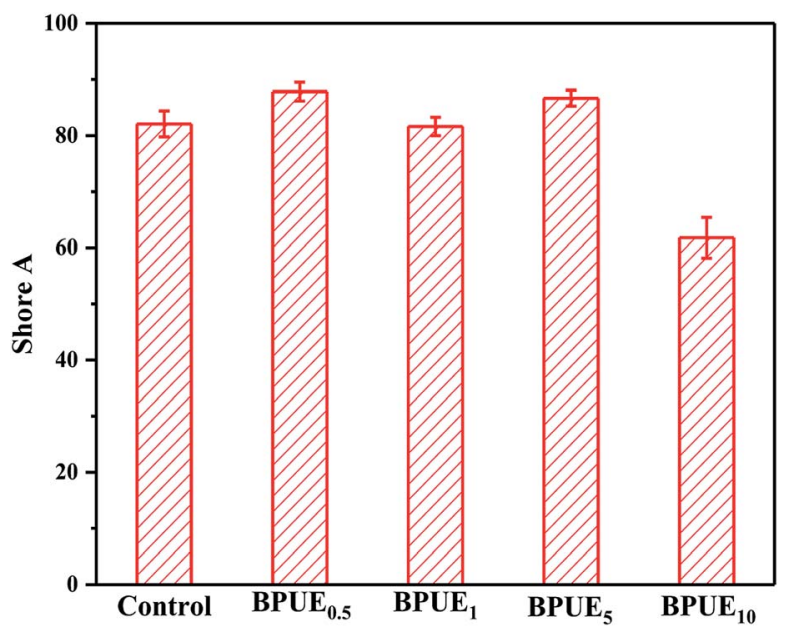

Fig. 11 Shore A hardness of PUEs films.

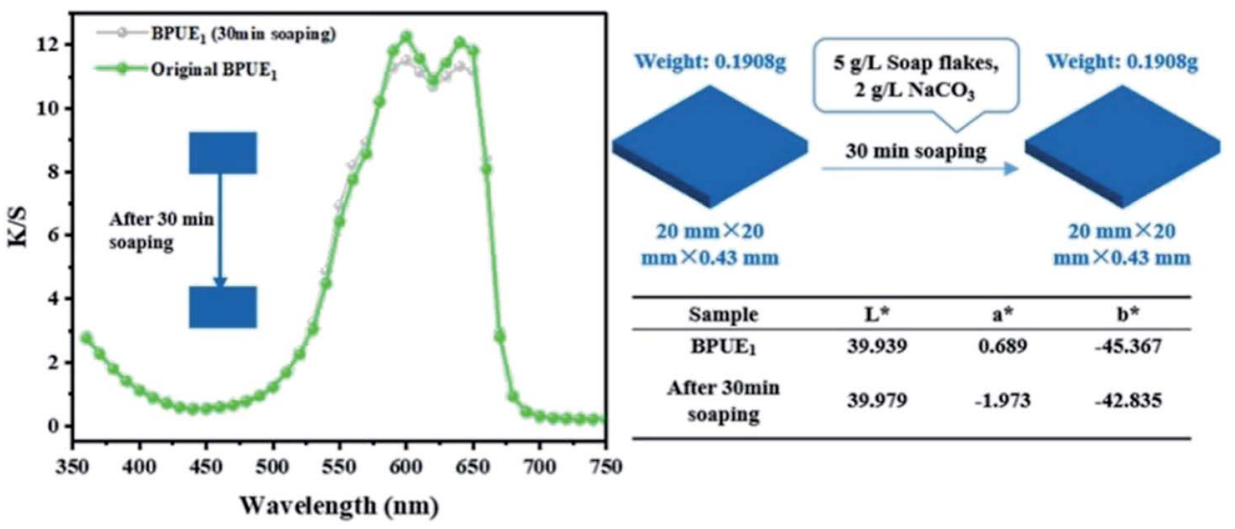

Fig. 10 Effect of washing on $K / S$ values and specimen dimensions of $B P U E_{1}$ films. 


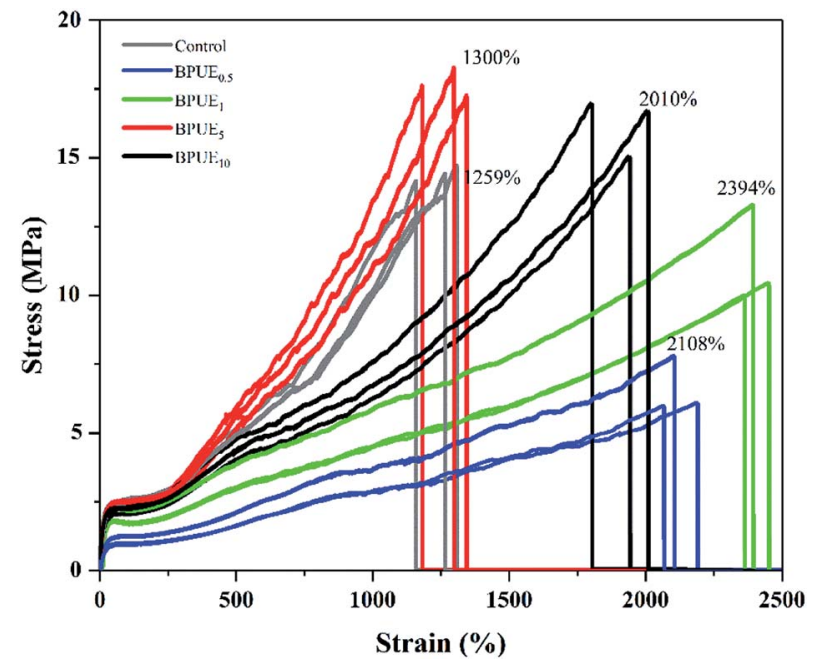

Fig. 12 Effects of chromogen addition mole ratio on the tensile behavior of PUEs.

\section{Mechanical property}

A unique feature of PUEs is that they can be processed to cover a wide range of hardness, which is an important mechanical property for PUEs. The hardness can be adjusted for the PUE films between Shore A 81-88 in Fig. 11. Shore A hardness of PUEs corresponding to different contents of chromogen is largely influenced by the content and the morphology of the hard phase, and the values are consistent with soft rubbers. ${ }^{34}$ The hardness of the PUE films are affected by many factors such as H-bonding, phase separation and crosslink density. In contrast, the Shore A hardness for BPUE $_{10}$ (10\% molar ratio chromogen) is much lower (Shore A 61.7), which may be caused by an overdose of chromogen affecting hydroxyl activity.

The mechanical properties of the PUE films are affected by the structural difference between control and BPUEs, crosslinking density and intermolecular interactions between their hard segments. The tensile-strain curves of control and BPUEs with different molar ratios of $\mathrm{NH}-$ blue-OH are shown in Fig. 12. Compared to the average strain of control sample (1259\%), it can be observed that the average strains of $\mathrm{BPUE}_{0.5}, \mathrm{BPUE}_{1}$, $\mathrm{BPUE}_{5}$, and $\mathrm{BPUE}_{10}$ are 2108\%, 2394\%, 1300\% and 2010\%, respectively. Meanwhile the average stresses of control, $\mathrm{BPUE}_{0.5}$, BPUE $_{1}$, BPUE $_{5}$, and BPUE $_{10}$ are $14.49 \mathrm{MPa}, 7.84 \mathrm{MPa}$, 13.38 MPa, 18.29 MPa and 16.71 MPa, respectively. The optimal stress-strain property is obtained from $\mathrm{BPUE}_{1}$, exhibiting a tensile stress at break of $13.35 \mathrm{MPa}$ and strain of $2394 \%$. The chemical cross-linking is the critical factors to result in the PUEs' high stretchability, meanwhile the synergistic combination of physical interactions is also the secondary cause, which includes $\pi-\pi$ stacking between segments, hydrogen bonding and crystallization of the soft segments. ${ }^{35,36}$ Fig. 13 illustrated the enhancement mechanisms of PUE films reinforced with chromogen as chain extender.

\section{Surface morphology}

The surface morphology of PUE films is analyzed with SEM and typical images are depicted in Fig. 14. The PUE films show a continuous and smooth surface. Compared to control PUE film, BPUEs display a relatively coarse and apparently phase separated morphology. Moreover, with the addition of $1.0 \mathrm{wt} \%$

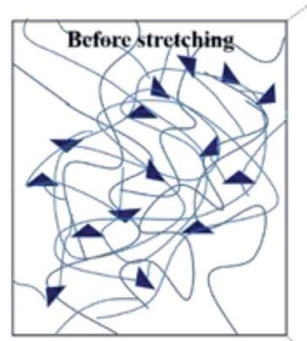

A Chromogen

Polyurethane Chain
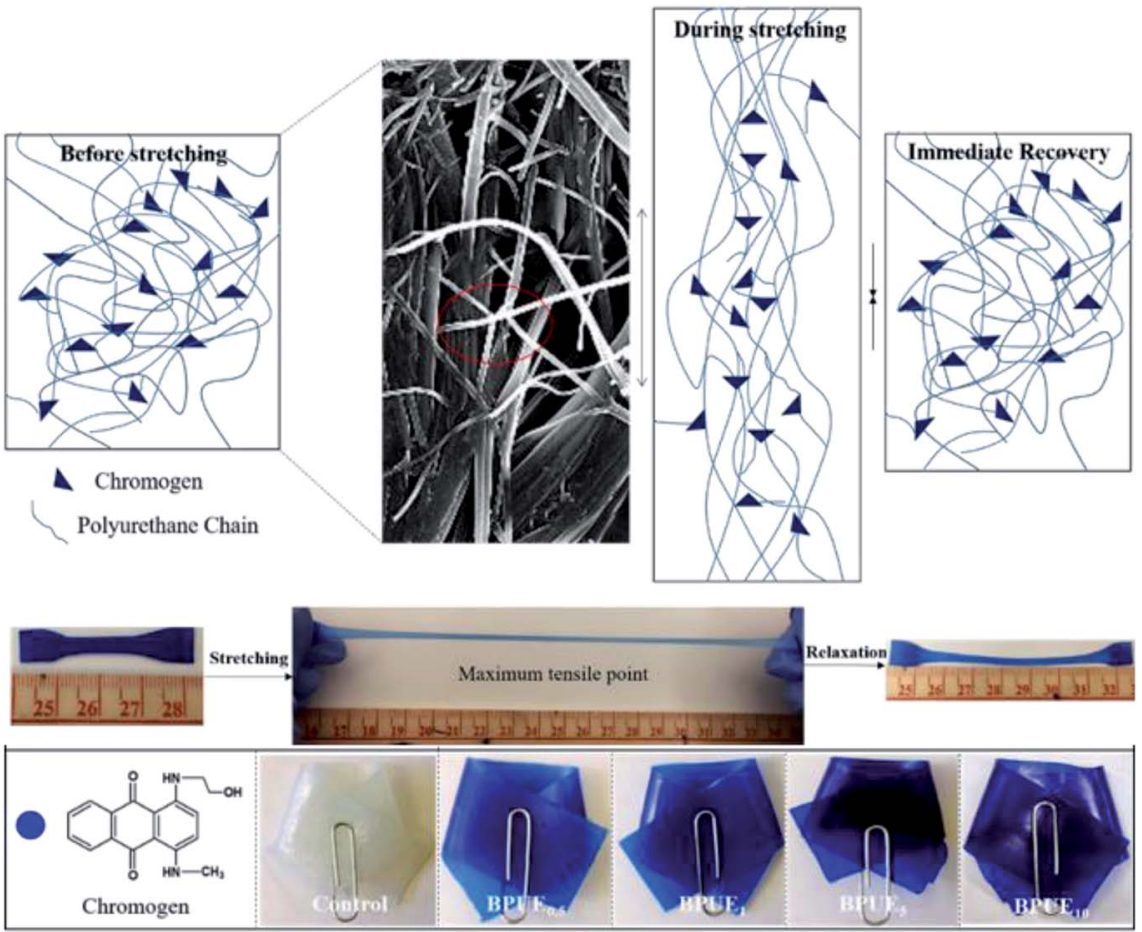

Fig. 13 Enhancement mechanisms of BPUE films. 

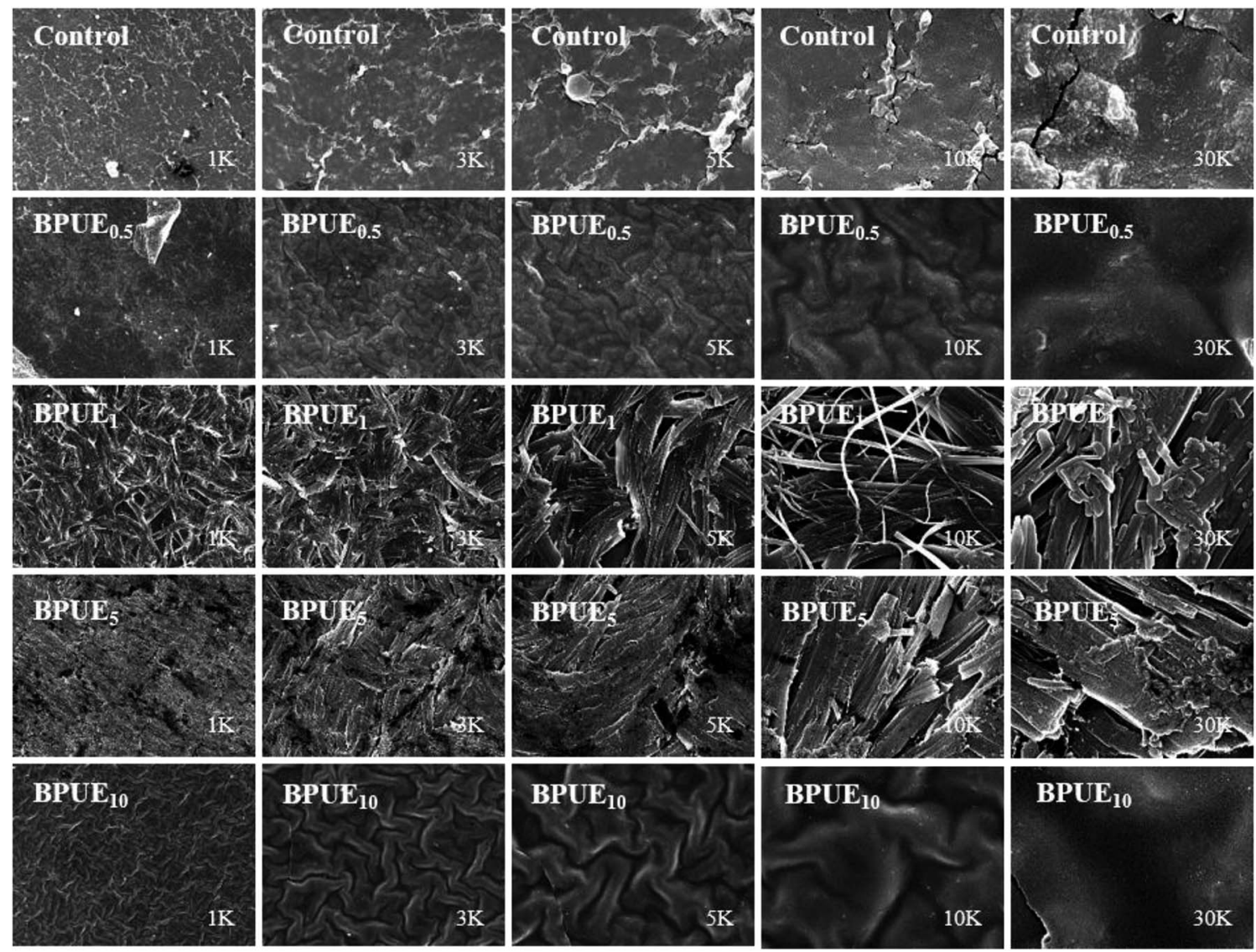

Fig. 14 Surface morphologies of the PUE films with different chromogen contents

chromogen, the micrograph become significantly rough of BPUE $_{1}$ are observed. The clear tortuous surface and entanglements are found in BPUEs. Chromogen induced phase separation and acted as cross-linkers, which improve the cohesion force between hard segments and suppress the spread of cracks, meanwhile the stiffness and toughness of BPUEs are enhanced.

\section{Thermal analysis}

The thermal behavior of the PUEs based on PCDL 2000 and PTHF 2000 with chromogen as chain extender was obtained from DSC curves as displayed in Fig. 15 and Table 6. PUEs (control, BPUE ${ }_{0.5}, \mathrm{BPUE}_{1}, \mathrm{BPUE}_{5}$, and BPUE ${ }_{10}$ ) exhibited $T_{\mathrm{g}} \mathrm{HS}$ (hard segment glass transition temperature) and $T_{\mathrm{g}} \mathrm{SS}$ (soft segment transition temperature) in the range of -39.48 to $-36.87{ }^{\circ} \mathrm{C}$ and $97.17-98.68{ }^{\circ} \mathrm{C}$, respectively, implying microphase separation between the hard and soft segments, which demonstrated a very slight difference between the samples. $T_{\mathrm{g}} \mathrm{SS}$ and $T_{\mathrm{g}} \mathrm{HS}$ are related to the flexibility of PUE segment. In general, higher $T_{\mathrm{g}}$ indicates that PUE contains more immobile segments. A relatively high $T_{\mathrm{g}} \mathrm{SS}$ was observed in the PUE because the hard segments were evenly dispersed in the PUE, which greatly limited the flexibility of soft segments. In fact, the lower $T_{\mathrm{g}} \mathrm{SS}$ generally correspond to the higher degree of phase separation in PUE. BPUEs exhibit a lower $T_{\mathrm{g}} \mathrm{SS}$, indicating that the addition of chromogen increase the phase separation between the soft and hard segments, thereby enhancing the mechanical properties of the PUE. On the other hand, with the increase amount of the chromogen, the strong interaction between the chromogen and the hard segment will bring more obstacles to the movement of the hard segment, which leads to the increase of $T_{\mathrm{g}} \mathrm{HS}$. The results showed the degree of microphase separation of PUE increased with the increase of chromogen amount.

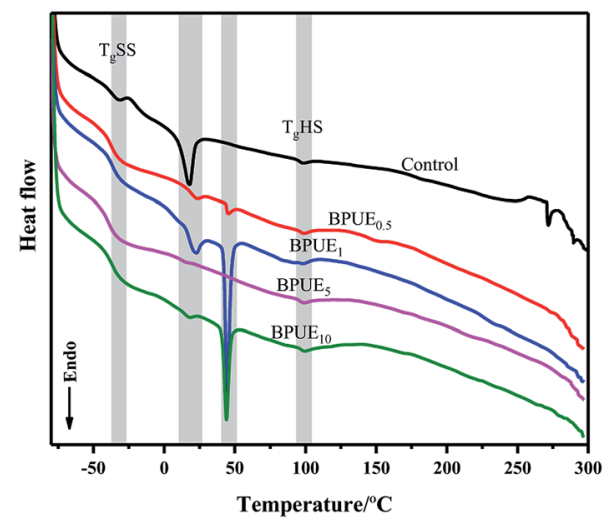

Fig. 15 DSC curves of PUEs. 
Table 6 Basic thermal parameters of control and BPUEs

\begin{tabular}{lllllllll}
\hline Sample & $T_{\mathrm{g} S S} /{ }^{\circ} \mathrm{C}$ & $T_{\mathrm{g} H S} /{ }^{\circ} \mathrm{C}$ & $T_{\mathrm{r} 1} /{ }^{\circ} \mathrm{C}$ & $\Delta H_{\mathrm{r} 1} /\left(\mathrm{J} \mathrm{g}^{-1}\right)$ & Phase transition & $T_{\mathrm{r} 2} /{ }^{\circ} \mathrm{C}$ & $\Delta H_{\mathrm{r} 2} /\left(\mathrm{J} \mathrm{g}^{-1}\right)$ & $\mathrm{Phase} \mathrm{transition}$ \\
\hline Control & -36.87 & 98.12 & 10.84 & 3.21 & Solid-solid & - & - & - \\
BPUE $_{0.5}$ & -37.83 & 98.68 & 15.51 & 0.51 & Solid-solid & 44.85 & 0.34 & Solid-solid \\
BPUE $_{1}$ & -36.89 & 97.17 & 14.99 & 1.32 & Solid-solid & 41.95 & 4.64 & Solid-solid \\
BPUE $_{5}$ & -39.48 & 98.68 & 13.77 & 0.07 & Solid-solid & - & - & - \\
BPUE $_{10}$ & -38.45 & 98.30 & 16.04 & 0.25 & Solid-solid & 39.92 & 3.02 & Solid-solid
\end{tabular}

\section{Conclusions}

In this work, PUEs (polyurethane elastomers) with excellent color properties and superb stretchability were successfully synthesized with anthraquinone chromogen as chain extender. The results of UV-Vis quantitative analysis, $K / S$ values and color fastnesses for PUEs confirm that anthraquinone chromogens were successfully introduced to PUE chains. Meanwhile, the PUE films exhibit high tinting strength and accomplish an excellent color fastness performance. The introduction of anthraquinone chromogens into polyurethane chain enhance the color strength and improve the color fastness. High tensile stress and strain are also achieved, especially for $\mathrm{BPUE}_{1}$ (1.0 wt\% chromogen) which shows high tensile stress (13.35 MPa) and very excellent strain (2394\%). FTIR, XRD and SEM results also suggest chromogen induced an improvement in phase separation which helps to enhance mechanical properties. This study provides us a facile approach to prepare BPUEs with excellent color properties and superb stretchability based on anthraquinone chromogen as chain extender for potential application. Based on the excellent properties of BPUEs, the potential applications of BPUEs were explored. As film materials, the excellent coloring properties, supreme mechanical performance and high-temperature processing properties have laid a foundation for their direct application in the textile field. It also provides a simple and feasible coloring method of aramid fabric. In order to overcome the hard/brittle and difficult coloring problems of polylactic acid (PLA), the BPUEs can be used as blending modifier to improve the mechanical properties of PLA and give PLA excellent color properties.

\section{Conflicts of interest}

There are no conflicts to declare.

\section{Acknowledgements}

The authors are grateful for the financial support of National Natural Science Foundation of China (21174055), Fundamental Research Funds for the Central Universities (JUSRP51724B), National First-Class Discipline Program of Light Industry Technology and Engineering (LITE2018-21), 111 Project (B17021), International Joint Research Laboratory for Advanced Functional Textile Materials of Jiangnan University, Postgraduate Research \& Practice Innovation Program of Jiangsu Province in China (KYCX17_1471).

\section{References}

1 S. Hsu, C. T. Hsieh and Y. M. Sun, J. Mater. Chem. B, 2015, 3, 9089-9097.

2 M. V. Pergal, J. Nestorov, G. Tovilović, S. Ostojić, D. Gođevac, D. Vasiljević-Radović and J. Djonlagić, J. Biomed. Mater. Res., Part A, 2014, 102, 3951-3964.

3 S. A. Guelcher, K. M. Gallagher, J. E. Didier, D. B. Klinedinst, J. S. Doctor, A. S. Goldstein, G. L. Wilkes, E. J. Beckman and J. O. Hollinger, Acta Biomater., 2005, 1, 471-484.

4 Y. Chen, Y. Li, D. Xu and W. Zhai, RSC Adv., 2015, 5, 8203482041.

5 D. V. Anokhin, M. A. Gorbunova, Y. I. Estrin, V. V. Komratova and E. R. Badamshina, Phys. Chem. Chem. Phys., 2016, 18, 31769-31776.

6 B. Fernández-d'Arlas, J. Balko, R. P. Baumann, E. Pöselt, R. Dabbous, B. Eling and T. Thurn-Albrecht, Macromolecules, 2016, 49, 7952-7964.

7 S. A. Madbouly, Y. Xia and M. R. Kessler, Macromolecules, 2013, 46, 4606-4616.

8 J. A. Miller, S. B. Lin, K. K. Hwang, K. S. Wu, P. E. Gibson and S. L. Cooper, Macromolecules, 1985, 18, 32-44.

9 C. Zhang, S. A. Madbouly and M. R. Kessler, ACS Appl. Mater. Interfaces, 2015, 7, 1226-1233.

10 P. K. Behera, K. M. Usha, P. K. Guchhait, D. Jehnichen, A. Das, B. Voit and N. K. Singha, RSC Adv., 2016, 6, 9940499413.

11 V. V. Tereshatov and V. Y. Senichev, J. Macromol. Sci., Part B: Phys., 2014, 53, 575-587.

12 Q. Liu, L. Jiang, R. Shi and L. Zhang, Prog. Polym. Sci., 2012, 37, 715-765.

13 R. G. Heijkants, R. V. van Calck, T. G. van Tienen, J. H. de Groot, P. Buma, A. J. Pennings, R. P. Veth and A. J. Schouten, Biomaterials, 2005, 26, 4219-4228.

14 Z. Liu, Y. Luo, H. Bai, Q. Zhang and Q. Fu, ACS Sustainable Chem. Eng., 2015, 4, 111-120.

15 M. J. Wiggins, M. MacEwan, J. M. Anderson and A. Hiltner, J. Biomed. Mater. Res., Part A, 2004, 68, 668-683.

16 H. S. Lee, Y. K. Wang and S. L. Hsu, Macromolecules, 1987, 20, 2089-2095.

17 C. W. Meuse, X. Yang, D. Yang and S. L. Hsu, Macromolecules, 1992, 25, 925-932.

18 S. Mondal and J. L. Hu, J. Membr. Sci., 2006, 274, 219-226.

19 J. K. Yun, H. J. Yoo and H. D. Kim, J. Appl. Polym. Sci., 2007, 105, 1168-1176.

20 A. Mukhopadhyay and V. K. Midha, Handbook of Technical Textiles, 2016, pp. 27-55. 
21 R. Narayan, D. K. Chattopadhyay, B. Sreedhar, K. V. S. N. Raju, N. N. Mallikarjuna and T. M. Aminabhavi, J. Appl. Polym. Sci., 2016, 99, 368-380.

22 S. Hollande and J. L. Laurent, J. Appl. Polym. Sci., 1999, 73, 2525-2534.

23 E. Y. Kim, J. H. Lee, D. J. Lee, Y. H. Lee, J. H. Lee and H. D. Kim, J. Appl. Polym. Sci., 2013, 129, 1745-1751.

24 S. J. Choi, J. H. Lee, Y. H. Lee, D. Y. Hwang and H. D. Kim, J. Appl. Polym. Sci., 2011, 121, 3516-3524.

25 J. Su, X. Zhang, J. Dai and J. Zhang, J. Dispersion Sci. Technol., 2012, 33, 1373-1378.

26 H. Mao, C. Wang and Y. Wang, New J. Chem., 2015, 39, 35433550 .

27 F. Yang, C. W. Y. Wang, D. Yao and Y. Yin, $R S C A d v .$, 2015, 5, 30631-30639.

28 H. Mao, S. Qiang, F. Yang, C. Zhao, C. Wang and Y. Yin, J. Appl. Polym. Sci., 2015, 132, 42780.
29 H. Mao, S. Qiang, Y. Xu and C. Wang, New J. Chem., 2017, 41, 619-627.

30 C. Wang, Y. Zheng, Y. Sun, J. Fan, Q. Qin and Z. Zhao, Polym. Chem., 2016, 7, 6120-6132.

31 H. Xia and M. Song, Soft Matter, 2005, 1, 386-394.

32 M. Amrollahi, G. M. M. Sadeghi and Y. Kashcooli, Mater. Des., 2011, 32, 3933-3941.

33 J. Chen, B. Guo, T. W. Eyster and P. X. Ma, Chem. Mater., 2015, 27, 5668-5677.

34 I. Fink, B. Eling, E. Pöselt and G. A. Luinstra, J. Polym. Sci., Part A: Polym. Chem., 2018, 56, 1162-1172.

35 J. Li, L. Ma, G. Chen, Z. Zhou and Q. Li, J. Mater. Chem. B, 2015, 3, 8401-8409.

36 Y. Wang, T. Li, X. Wang, P. Ma, H. Bai, W. Dong, Y. Xie and M. Chen, Biomacromolecules, 2016, 17, 3782-3789. 